\title{
Enhanced cellular uptake of aminosilane-coated superparamagnetic iron oxide nanoparticles in mammalian cell lines
}

This article was published in the following Dove Press journal:

International Journal of Nanomedicine

20 February 2012

Number of times this article has been viewed

\author{
Xiao-Ming Zhu' \\ Yi-Xiang J Wang' \\ Ken Cham-Fai Leung ${ }^{2,3}$ \\ Siu-Fung Lee ${ }^{2}$ \\ Feng Zhao' \\ Da-Wei Wang ${ }^{2}$ \\ Josie MY Lai ${ }^{4}$ \\ Chao Wan ${ }^{4}$ \\ Christopher HK Cheng ${ }^{4}$ \\ Anil T Ahuja' \\ 'Department of Imaging and \\ Interventional Radiology, Prince \\ of Wales Hospital, The Chinese \\ University of Hong Kong, Shatin, \\ NT, Hong Kong SAR; ${ }^{2}$ Institute of \\ Molecular Functional Materials \\ and Department of Chemistry, The \\ Chinese University of Hong Kong, \\ Shatin, NT, Hong Kong SAR; ${ }^{3}$ Institute \\ of Creativity and Department of \\ Chemistry, The Hong Kong Baptist \\ University, Kowloon Tong, Kowloon, \\ Hong Kong SAR; ${ }^{4}$ School of Biomedical \\ Sciences, The Chinese University of \\ Hong Kong, Shatin, NT, Hong Kong
}

Correspondence: Yi-Xiang J Wang

Department of Imaging and Interventional

Radiology, Prince of Wales Hospital,

The Chinese University of Hong Kong,

Shatin, NT, Hong Kong

Tel + 85226322289

Fax +852 26360012

Email yixiang_wang@cuhk.edu.hk

Ken Cham-Fai Leung

Institute of Creativity and Department of Chemistry, The Hong Kong Baptist University, Kowloon Tong, Kowloon,

Hong Kong

Tel +85234 I I 2370

Fax +85234117348

Email cfleung@hkbu.edu.hk
Purpose: To compare the cellular uptake efficiency and cytotoxicity of aminosilane $\left(\mathrm{SiO}_{2}-\mathrm{NH}_{2}\right)$-coated superparamagnetic iron oxide $\left(\mathrm{SPIO} @ \mathrm{SiO}_{2}-\mathrm{NH}_{2}\right)$ nanoparticles with three other types of SPIO nanoparticles coated with $\mathrm{SiO}_{2}\left(\mathrm{SPIO} @ \mathrm{SiO}_{2}\right)$, dextran (SPIO@dextran), or bare SPIO in mammalian cell lines.

Materials and methods: Four types of monodispersed SPIO nanoparticles with a SPIO core size of $7 \mathrm{~nm}$ and an overall size in a range of 7-15 nm were synthesized. The mammalian cell lines of MCF-7, MDA-MB-231, HT-29, RAW264.7, L929, HepG2, PC-3, U-87 MG, and mouse mesenchymal stem cells (MSCs) were incubated with four types of SPIO nanoparticles for 24 hours in the serum-free culture medium Dulbecco's modified Eagle's medium (DMEM) with $4.5 \mu \mathrm{g} / \mathrm{mL}$ iron concentration. The cellular uptake efficiencies of SPIO nanoparticles were compared by Prussian blue staining and intracellular iron quantification. In vitro magnetic resonance imaging of MSC pellets after SPIO labeling was performed at $3 \mathrm{~T}$. The effect of each SPIO nanoparticle on the cell viability of RAW 264.7 (mouse monocyte/macrophage) cells was also evaluated.

Results: Transmission electron microscopy demonstrated surface coating with $\mathrm{SiO}_{2}-\mathrm{NH}_{2}, \mathrm{SiO}_{2}$, and dextran prevented SPIO nanoparticle aggregation in DMEM culture medium. MCF-7, MDA-MB-231, and HT-29 cells failed to show notable iron uptake. For all the remaining six cell lines, Prussian blue staining and intracellular iron quantification demonstrated that SPIO@, $\mathrm{SiO}_{2}-\mathrm{NH}_{2}$ nanoparticles had the highest cellular uptake efficiency. SPIO@ $\mathrm{SiO}-\mathrm{NH}_{2}$, bare SPIO, and SPIO@dextran nanoparticles did not affect RAW 264.7 cell viability up to $200 \mu \mathrm{g}$ Fe/mL, while SPIO@SiO, reduced RAW 264.7 cell viability from 10 to $200 \mu \mathrm{g} \mathrm{Fe} / \mathrm{mL}$ in a dose-dependent manner.

Conclusion: Cellular uptake efficiency of SPIO nanoparticles depends on both the cell type and SPIO surface characteristics. Aminosilane surface coating enhanced the cellular uptake efficiency without inducing cytotoxicity in a number of cell lines.

Keywords: magnetic nanoparticles, SPIO, iron oxide, surface coating, cellular uptake

\section{Introduction}

The use of nanoparticles for cellular imaging and drug-targeted delivery is likely to be one of most important clinical applications of nanotechnology. Therapeutic and diagnostic agents can be encapsulated, covalently attached, or adsorbed onto nanoparticles. In the mesoscopic size range of 5-100 $\mathrm{nm}$ diameter, nanoparticles possess large surface areas for conjugating to multiple diagnostic and therapeutic agents. Multi-pore nanoshells are also used for encapsulating drugs. When administrated in vivo, nanoparticles can accumulate preferentially at tumor sites through enhanced permeability and retention effect, ${ }^{1-3}$ as tumor-associated neovasculatures are highly permeable, allowing the 
leakage of circulating nanoparticles into the tumor interstitium, and also many tumors lack an effective lymphatic drainage, leading to subsequent nanoparticle accumulation. Drug resistance is also emerging as a major obstacle limiting the therapeutic efficacy of chemotherapeutic agents. Among several mechanisms of drug resistance, P-glycoprotein is the best known, whereas drugs associated with nanoparticles may avoid recognition by the P-glycoprotein efflux pump, leading to higher intracellular drug concentrations. ${ }^{4}$ As an example of one clinical application of nanotechnology, in a new formulation approach used in Abraxane ${ }^{\circledR}$ (Celgene Corporation, Summit, NJ), paclitaxel was conjugated to albumin nanoparticles to treat metastatic breast cancer. ${ }^{5}$

Superparamagnetic iron oxide (SPIO) nanoparticles are one of the most studied biomaterials. To date, dextran-coated SPIO nanoparticles, namely ferumoxides (Feridex ${ }^{\circledR}$ [Amag Pharmaceuticals, Inc, Cambridge, MA]/Endorem ${ }^{\circledR}$ [Guerbet, Paris, France]) and ferucarbotran (Resovist ${ }^{\circledR}$, Schering AG, Berlin, Germany) are clinically approved for liver magnetic resonance imaging (MRI). In addition, carboxydextrancoated SPIO nanoparticles of ferumoxtran (Sinerem ${ }^{\circledR}$, Guerbet) have undergone clinical trials for MRI evaluation of lymph node metastasis. ${ }^{6-8}$ SPIO nanoparticles have further important potential for in vivo stem cell tracking, ${ }^{9,10}$ magnetic separation, ${ }^{11}$ hyperthermia therapy, ${ }^{12}$ and anticancer drug delivery. ${ }^{13-16}$ For many of these applications, optimized cellular uptake of SPIO nanoparticles by target cells is a critical step. One strategy to modulate the cellular uptake efficiency or specificity of SPIO nanoparticles is to modify their surface coating. In addition to dextran and carboxydextran, a number of surface coatings for SPIO nanoparticles, including polyethylene glycol (PEG), polyvinyl alcohol (PVA), dendrimers, starch, and silica, have been reported..$^{7,14,17}$ Among these coating materials, silica is regarded as a biocompatible material. ${ }^{18}$ Bioglass, which contains silica (ca 60 mol\%), calcium, and phosphorus, has many applications in wound healing, both in bone (hard) and soft tissues, middle ear implants, and in dentistry. ${ }^{19}$ Silica coating has the advantages of preventing the aggregation of particles in liquid and improvement of their chemical stability. ${ }^{20}$ Moreover, the silica coating of nanoparticles can be terminated by a variety of functional groups which can be covalently attached to specific ligands by various coupling agents. ${ }^{21}$

Organosilanes such as tetraethyl orthosilicate (TEOS), ${ }^{22-24}$ aminopropyltriethoxysilane (APTES), ${ }^{25}$ or (3-aminopropyl) trimethoxysilane (APTMS) ${ }^{26}$ are commonly used to produce functionalized thin films of silica coatings on nanoparticles in a variety of applications. Among them, APTES is one of the most frequently used to produce the aminosilane $\left(\mathrm{SiO}_{2}-\mathrm{NH}_{2}\right)$ coating to enhance protein and cell adhesion. ${ }^{27,28} \mathrm{SiO}_{2}-\mathrm{NH}_{2}-$ coated SPIO ( $\mathrm{SPIO} @ \mathrm{SiO}_{2}-\mathrm{NH}_{2}$ ) nanoparticles prepared by alkaline hydrolysis of APTES have been reported by the present authors ${ }^{29}$ and other groups. ${ }^{30-32}$ In a previous study, $\mathrm{SPIO} @ \mathrm{SiO}_{2}-\mathrm{NH}_{2}$ nanoparticles were applied to rabbit mesenchymal stem cell (MSC) labeling. ${ }^{29}$ It was shown that SPIO@, $\mathrm{SiO}_{2}-\mathrm{NH}_{2}$ nanoparticles had a higher labeling efficiency than $\mathrm{SiO}_{2}$-coated SPIO (SPIO@ $\mathrm{SiO}_{2}$ ) nanoparticles. However, whether SPIO@ $\mathrm{SiO}_{2}-\mathrm{NH}_{2}$ nanoparticles offer a universally higher internalization efficiency than other surface coatings in different mammalian cell lines remains unknown. In this present study, the authors attempted to evaluate and compare the intracellular uptake of $\mathrm{SPIO} @ \mathrm{SiO}_{2}-\mathrm{NH}_{2}$ with three other nanoparticles, namely SPIO@ $\mathrm{SiO}_{2}$, bare SPIO, and dextrancoated SPIO (SPIO@dextran) nanoparticles, in a variety of common mammalian cell lines.

\section{Material and methods Synthesis and characterization of SPIO nanoparticles}

Ferric chloride hexahydrate $\left(\mathrm{FeCl}_{3} \cdot 6 \mathrm{H}_{2} \mathrm{O}\right)$, ferrous sulfate heptahydrate $\left(\mathrm{FeSO}_{4} \cdot 7 \mathrm{H}_{2} \mathrm{O}\right)$, sodium hydroxide, anhydrous absolute ethanol, ammonia solution (20\%), APTES, tetraethyl orthosilicate (TEOS), and dextran $(70 \mathrm{kDa})$ were purchased from Sigma-Aldrich (St Louis, MO) or Acros Organics (Pittsburg, PA). For SPIO nanoparticle synthesis, the iron oxide core was synthesized by alkaline co-precipitation of two equivalents of ferric chloride and one equivalent of ferrous sulfate in sodium hydroxide solution protected by nitrogen gas under shaking. ${ }^{33}$ The precipitate was separated with a magnet and washed with deoxygenated water. The SPIO nanoparticles were heated at $120^{\circ} \mathrm{C}$ for 12 hours, and then the products were collected by a magnet and washed with deoxygenated water for further usage.SPIO@SiO and $\mathrm{SPIO} @ \mathrm{SiO}_{2}-\mathrm{NH}_{2}$ nanoparticles were produced by the hydrolysis reaction on the surfaces of SPIO nanoparticles using TEOS or APTES, ${ }^{31}$ respectively.

ForSPIO@dextran nanoparticle preparation, dextran with a molecular weight of $70 \mathrm{kDa}$ was first dissolved in a sodium hydroxide solution and refluxed for 2 hours. This solution was then added drop-wise to the ultrasonically dispersed SPIO nanoparticles in water with the $\mathrm{pH}$ value adjusted to 3. The mixture was stirred and refluxed for 30 minutes. The products were separated with a magnet and washed with deoxygenated water.

The morphology of synthesized SPIO nanoparticles were characterized under a transmission electron microscope (TEM) 
(Philips CM-120; Philips, Amsterdam, The Netherlands), and the diameter for each kind of SPIO nanoparticle was measured. Fourier transform infrared (FT-IR) spectra of each synthesized SPIO nanoparticles were studied to confirm the presence of specific surface coating with wave numbers in a range of 500-4000 $\mathrm{cm}^{-1}$ by a FT-IR spectrometer (Nicolet 670, Madison, WI), using a potassium bromide wafer. A Beckman Coulter Delsa 440SX zeta-potential analyzer was used to determine the zeta potential of the SPIO nanoparticles. Measurements were performed in $10 \mathrm{mM}$ Hepes buffer at $\mathrm{pH}$ 7.4.

\section{SPIO nanoparticle stability in culture medium}

To determine the dispersible property of each kind of nanoparticle under the culture medium Dulbecco's Modified Eagle Medium (DMEM) (Invitrogen, Carlsbad, CA), each nanoparticle was added into the DMEM without serum, followed by incubation at $37^{\circ} \mathrm{C}$ for 1 hour. The SPIO nanoparticles with or without incubation in DMEM medium were added onto the carbon-coated copper grid. The sample grids were dried prior to TEM.

\section{In vitro MRI relativity measurement}

Magnetic resonance relaxometry of the nanoparticles was performed by using a clinical $1.5 \mathrm{~T}$ whole-body MRI system (Siemens Sonata, Erlangen, Germany) in combination with a knee radio frequency coil for excitation and signal reception. Four SPIO nanoparticle samples were dispersed in distilled $\mathrm{H}_{2} \mathrm{O}$ at iron concentrations in a range from 0.1 to $10.0 \mu \mathrm{g} / \mathrm{mL}$. For magnetic resonance measurements, dispersed SPIO nanoparticle solutions $(1.0 \mathrm{~mL})$ at different concentrations were filled in each Eppendorf tube $(1.5 \mathrm{~mL})$. Sonication was applied for 10 minutes prior to MRI. $T_{2}$ relaxation times were measured by using a standard Carr-Purcell-Meiboom-Gill pulse sequence (repetition time $[\mathrm{TR}]=2000$ milliseconds, echo time $[\mathrm{TE}]$ range $=30-960 \mathrm{~ms}, 32$ echoes, field-ofview $\left[\right.$ FOV] $=134 \times 67 \mathrm{~mm}^{2}$, matrix $=128 \times 64$, slice thickness $=5 \mathrm{~mm}$, number of excitations $=3$ ). $T_{2}$ relaxation times were calculated by a linear fit of the logarithmic region off interest signal amplitudes versus TE. The $T_{2}$ relaxivities $\left(r_{2}\right)$ were determined by a linear fit of the inverse relaxation times as a function of the iron concentrations used.

\section{Cell culture}

The breast cancer cells (MCF-7), MDA-MB-231 cells, colon cancer cells (HT-29), mouse macrophage cells (RAW 264.7), mouse fibroblast cells (L929), human hepatoma cells
(HepG2), human prostate cancer cells (PC-3), and human glioblastoma cells (U-87 MG) were obtained from American Type Culture Collection (ATCC, Manassas, VA) and cultured with DMEM (Invitrogen) containing 10\% fetal bovine serum (FBS), $100 \mathrm{U} / \mathrm{mL}$ penicillin, and $100 \mu \mathrm{g} / \mathrm{mL}$ streptomycin at $37^{\circ} \mathrm{C}$ and in a humidified $5 \% \mathrm{CO}_{2}$ atmosphere. The MSCs were primarily derived from mouse bone marrow under the following procedures. ${ }^{34}$ Under sterilized conditions, bone marrow was harvested with phosphate-buffered saline (PBS) from tibia and femoral medullary cavity flushes of 4-week-old C57BL/6 mice (Jackson Labs, Bar Harbor, ME). Mononuclear cells were isolated by density gradient centrifugation and cultured with $\alpha$-MEM (alpha-modified minimum essential medium) containing 20\% FBS, $100 \mathrm{U} / \mathrm{mL}$ penicillin, and $100 \mu \mathrm{g} / \mathrm{mL}$ streptomycin in the incubator. MSC colonies were further expanded; passage three MSCs were used for further experiments.

\section{Cellular labeling of SPIO nanoparticles}

About 5000-10,000 of each type of cell were seeded into each well of the 24-well plates. After 12 hours of incubation, the culture medium was replaced with the serum-free DMEM containing different types of SPIO nanoparticles with $4.5 \mu \mathrm{g} / \mathrm{mL}$ iron concentration. The cells were further incubated for 24 hours. Iron concentration of $4.5 \mu \mathrm{g} / \mathrm{mL}$ was used based on the results of a previous publication. ${ }^{29}$ The pilot study confirmed iron concentration of $4.5 \mu \mathrm{g} / \mathrm{mL}$ did not affect the cell viability of any cell lines used in this study. The pilot study also observed that $>10 \mu \mathrm{g} \mathrm{Fe} / \mathrm{mL}$ of SPIO nanoparticles did not enhance cell uptake efficiency, whereas at very high concentrations, such as $50 \mu \mathrm{g} \mathrm{Fe} / \mathrm{mL}$, nanoparticles tended to aggregate in the culture medium and to adhere to the plastic plate bottom.

\section{Prussian blue staining for SPIO nanoparticle-labeled cells}

After incubation with SPIO nanoparticles, the cells were washed with PBS to remove any free SPIO nanoparticles. Cells were fixed for 40 minutes using 4\% paraformaldehyde (Sigma-Aldrich). Then, cells were washed with PBS and incubated with fresh prepared Perls' reagent $(4 \%$ potassium ferrocyanide [Sigma-Aldrich]/12\% $\mathrm{HCl}, 1: 1$, $\mathrm{v} / \mathrm{v})$ for 30 minutes. The cells were washed three times with PBS, counterstained with neutral red (0.02\%) (SigmaAldrich), and subsequently observed by an inverted optical microscope. ${ }^{35,36}$ For each cell line, the comparative labeling efficiency of each type of SPIO nanoparticle was assessed visually by two readers (XMZ, 7 years experience of 
cell biology and 2 years experience of reading SPIO cell labeling; and YXJW, 3 years experience of cell biology and 3 years experience of reading SPIO cell labeling), and consensus was reached. The experiment was carried out three times. With Prussian blue staining assessment, MCF-7 cells, MDA-MB-231 cells, and HT-29 cells failed to show notable iron uptake, and were thereafter excluded from further studies.

\section{Intracellular iron content measurement}

Colorimetric method was used to study the iron concentration for SPIO nanoparticles or cell samples labeled by SPIO nanoparticles. ${ }^{37}$ For the intracellular iron content quantification, after the cells were incubated with SPIO nanoparticles with $4.5 \mu \mathrm{g} / \mathrm{mL}$ iron concentration for 24 hours, the cells were washed, collected, and counted. After $4500 \mathrm{~g}$ centrifugation for 5 minutes, the collected cell pellets were dispensed in $100 \mu \mathrm{L} 12 \% \mathrm{HCl}$ solution and incubated at $60^{\circ} \mathrm{C}$ for 4 hours. After incubation, the suspension was centrifuged at $12,000 \times g$ for 10 minutes, and the supernatants were collected for iron concentration quantification. A volume of $50 \mu \mathrm{L}$ of sample solution was added into the wells of a 96-well plate, and then $50 \mu \mathrm{L}$ of $1 \%$ ammonium persulfate (Sigma-Aldrich) was added to oxidize the ferrous ions to ferric ions. ${ }^{38}$ Finally, $100 \mu \mathrm{L}$ of $0.1 \mathrm{M}$ potassium thiocyanate (Sigma-Aldrich) was added to the solution and incubated for 5 minutes to form the red color iron-thiocyanate. The absorption was read by a microplate reader (Model 3550; Bio-Rad, Richmond, CA) at a wavelength of $490 \mathrm{~nm}$.

\section{In vitro MRI of mouse MSCs labeled with SPIO nanoparticles}

In vitro MRI was performed with mouse MSCs labeled with the four types of SPIO nanoparticles $(4.5 \mu \mathrm{g} \mathrm{Fe} /$ $\mathrm{mL}$ ) for 24 hours. After washing with PBS, the cells were trypsinized and counted. Different numbers $\left(0,1 \times 10^{3}\right.$, $3 \times 10^{3}, 6 \times 10^{3}, 1 \times 10^{4}, 3 \times 10^{4}, 6 \times 10^{4}, 1 \times 10^{5}$, or $\left.3 \times 10^{5}\right)$ of cells were placed in an Eppendorf tube $(1.5 \mathrm{~mL})$. After centrifugation at $4000 \mathrm{rpm}$ for 5 minutes, the Eppendorf tubes were placed perpendicular to the main magnetic induction field $\left(B_{0}\right)$ in a $20 \mathrm{~cm} \times 12 \mathrm{~cm} \times 8 \mathrm{~cm}$ water bath. MRI was performed with a $3.0-\mathrm{T}$ clinical whole-body magnetic resonance unit (Achieva; Philips Medical Systems, Best, The Netherlands), using a transmit-receive head coil. The magnetic resonance sequence was a two-dimensional gradient-echo sequence with $\mathrm{TR} / \mathrm{TE}=400 / 48$ milliseconds, flip angle $=18^{\circ}$, matrix $=512 \times 256$, resolution $=0.45 \times 0.45 \mathrm{~mm}$, slice thickness $=2 \mathrm{~mm}$, and number of excitations $=2$. Sagittal images were obtained through the central section of the bottom tips of the Eppendorf tubes. The areas of signal void at the bottom of the Eppendorf tubes due to SPIO nanoparticle-labeled cell pellets were compared visually by a radiologist (YXJW) with past experience. ${ }^{29,39}$

\section{Biocompatibility assay}

The cytotoxicity of each different type of SPIO nanoparticle was examined by methylthiazolyldiphenyl-tetrazolium bromide (MTT) assay $^{40}$ in RAW 264.7 cells. A total of 10,000 RAW 264.7 cells were seeded into the wells of a 96-well plate. After 12 hours incubation, the medium in the wells was replaced with $100 \mu \mathrm{L}$ serum-free DMEM containing different iron concentrations $(0,10,20,50,100$, or $200 \mu \mathrm{g} / \mathrm{mL})$ of each SPIO nanoparticle. After 24 hours incubation, cells were washed with PBS once, and $100 \mu \mathrm{L}$ fresh medium containing $0.5 \mathrm{mg} /$ mL MTT (Sigma-Aldrich, St Louis, MO) was added into each well. After 3 hours incubation, the medium was removed, and formazan crystals were dissolved with $150 \mu \mathrm{L}$ dimethyl sulfoxide for 10 minutes on a shaker. A flat magnet was put under the plate to attract the magnetic particles to the bottom of the well. Then, $100 \mu \mathrm{L}$ of supernatant was transferred to another 96-well plate. The absorbance of each well was measured by a microplate reader (Model 3550, Bio-Rad, Richmond, CA) at a wavelength of $540 \mathrm{~nm}$. The relative cell viability (\%) for each sample related to control well was calculated.

\section{Statistical analysis}

Data were presented as mean \pm standard deviation. Statistical difference was evaluated with Mann-Whitney test or oneway analysis of variance. $P$ values $<0.05$ were considered statistically significant.

\section{Results}

\section{Characterization of synthesized SPIO nanoparticles}

Monodispersed SPIO@ $\mathrm{SiO}_{2}-\mathrm{NH}_{2}, \mathrm{SPIO} @ \mathrm{SiO}_{2}$, bare SPIO, and SPIO@dextran nanoparticles were successfully synthesized, as TEM images showed (Figure 1A). These four types of nanoparticles possessed a similar SPIO core size of $7 \mathrm{~nm}$, and together with their coating, the overall sizes ranged from 7 to $15 \mathrm{~nm}$. FT-IR spectra for each type of SPIO nanoparticle are shown in Figure 2. The typical absorbance band of Fe-O stretching vibration at $580 \mathrm{~cm}^{-1}$ could be found in all IR spectra. The broad peak that appeared in the region of $3200-3600 \mathrm{~cm}^{-1}$ corresponds to the $\mathrm{O}-\mathrm{H}$ stretching vibration as the bare SPIO nanoparticle (Figure 2C) surfaces were 

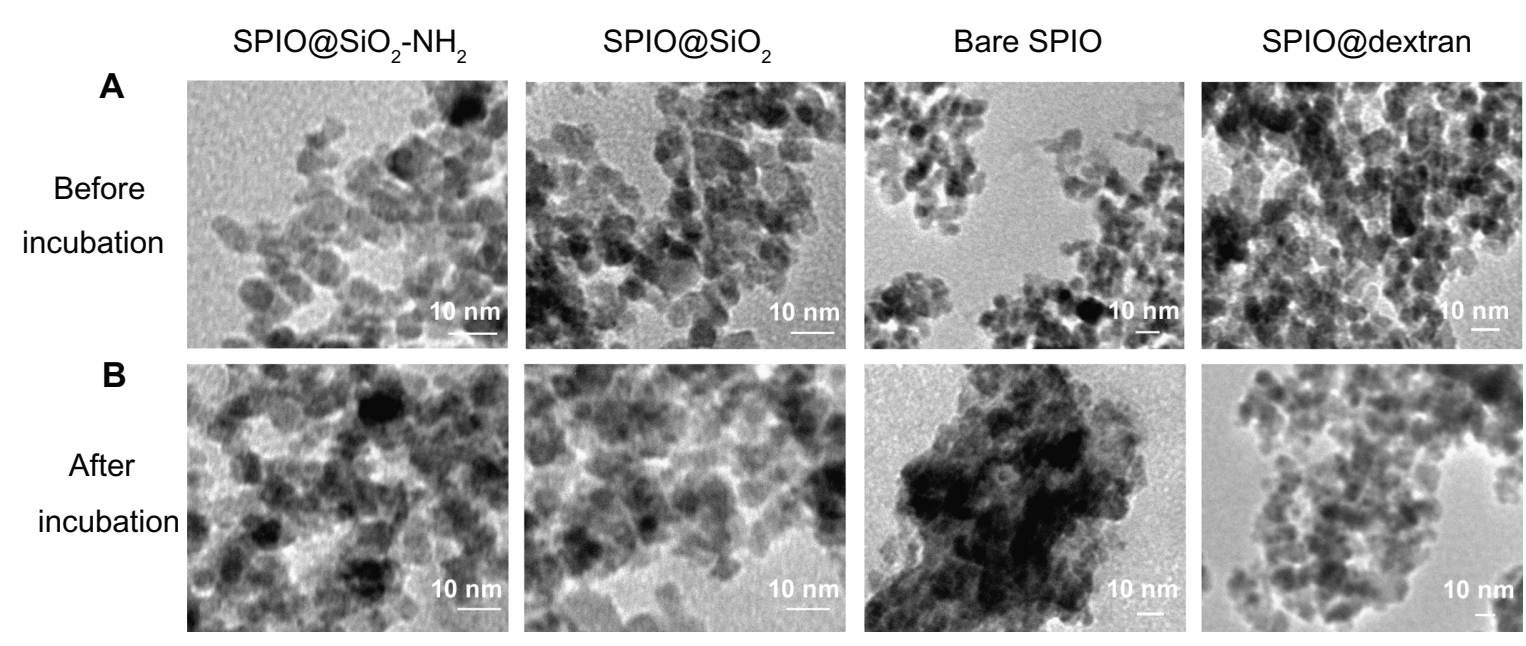

Figure I Transmission electron microscopy images of synthesized SPIO@SiO $2-\mathrm{NH}_{2}, \mathrm{SPIO} @ \mathrm{SiO}_{2}$, bare SPIO, and SPIO@dextran (A) and after I hour incubation in Dulbecco's modified Eagle's medium (B).

Notes: Dark dots represent the core of a single SPIO nanoparticle measuring approximately $7 \mathrm{~nm}$ in diameter. The coating is observed as a thin and white layer around each single iron oxide core. Bare SPIO nanoparticles tended to aggregate together in the culture medium; however, SPIO@SiO $-\mathrm{NH}_{2}, \mathrm{SPIO} @ \mathrm{SiO}$, and SPIO@dextran nanoparticles remained monodispersed.

Abbreviations: SPIO, superparamagnetic iron oxide; SPIO@SiO $-\mathrm{NH}_{2}$, aminosilane-coated SPIO nanoparticles; SPIO@SiO , SiO - -coated SPIO nanoparticles; SPIO@dextran, dextran-coated SPIO nanoparticles.

readily covered with hydroxyl groups. ${ }^{41}$ The IR spectra of $\mathrm{SPIO} @ \mathrm{SiO}_{2}-\mathrm{NH}_{2}$ (Figure 2A) and $\mathrm{SPIO} @ \mathrm{SiO}_{2}$ (Figure 2B) nanoparticles exhibited a broad absorption band centered at $1050 \mathrm{~cm}^{-1}$, which were coming from the vibrations of the Si-O-Si network, and suggested that the SPIO nanoparticles were encapsulated by a layer of silica. The N-H stretching from the amino groups of APTES was suggested to give a

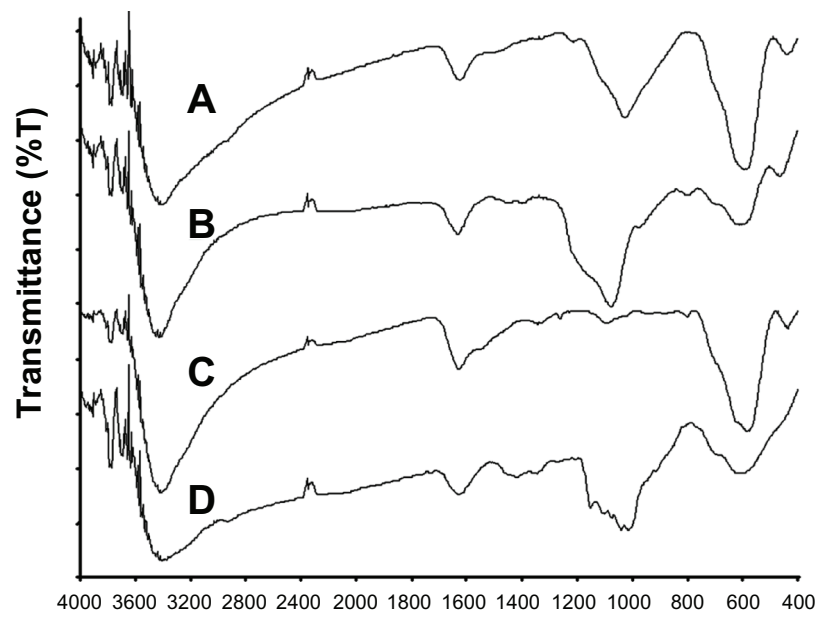

\section{Wavenumber $\left(\mathrm{cm}^{-1}\right)$}

Figure 2 Fourier transform infrared spectra of $\mathrm{SPIO} @ \mathrm{SiO}_{2}-\mathrm{NH}_{2}(\mathbf{A}), \mathrm{SPIO} @ \mathrm{SiO}_{2}$ (B), bare SPIO (C), and SPIO@dextran (D) nanoparticles.

Notes: The broad absorption band at $1050 \mathrm{~cm}^{-1}$ originates from the vibrations of $\mathrm{Si}-\mathrm{O}-\mathrm{Si}$ network. The complex absorption band in the region of $1200-1000 \mathrm{~cm}^{-1}$ indicates the dextran coating.

Abbreviations: $\mathrm{SPIO}$, superparamagnetic iron oxide; $\mathrm{SPIO} @ \mathrm{SiO}_{2}-\mathrm{NH}_{2}$, aminosilanecoated SPIO nanoparticles; SPIO@SiO, $\mathrm{SiO}_{2}$-coated SPIO nanoparticles; SPIO@ dextran, dextran-coated SPIO nanoparticles. broad peak at $3300-3500 \mathrm{~cm}^{-1}$; 42 however, this signal was masked by the broad hydroxyl vibrations. Nevertheless, the presence of amine could be confirmed by a previous electrodiagnostic study, which showed the presence of nitrogen element in SPIO@ $\mathrm{SiO}_{2}-\mathrm{NH}_{2}$ nanoparticles. ${ }^{29}$ In addition, the IR spectrum of SPIO@dextran (Figure 2D) nanoparticles showed a complex absorption band with several maxima in the region between 1200 and $1000 \mathrm{~cm}^{-1}$, in which these bands are commonly found in most carbohydrate derivatives including dextran, suggesting these SPIO nanoparticles were effectively coated with dextran. At $\mathrm{pH} 7.4$, the zeta potentials were $11.8 \pm 8.4,-35.8 \pm 16.4,-38.5 \pm 17.7 \mathrm{mV}$, and $-6.9 \pm 5.6 \mathrm{mV}$ for $\mathrm{SPIO} @ \mathrm{SiO}_{2}-\mathrm{NH}_{2}, \mathrm{SPIO} @ \mathrm{SiO}_{2}$, bare SPIO, and SPIO@dextran nanoparticles, respectively. The in vitro stability assay in culture medium indicated that the bare SPIO nanoparticles aggregated after 1 hour DMEM incubation (Figure 1B). However, $\mathrm{SiO}_{2}-\mathrm{NH}_{2}, \mathrm{SiO}_{2}$, and dextran coatings prevented severe aggregation of nanoparticles, and these nanoparticles remained well dispersed (Figure 1B). The MRI relaxivities $\left(r_{2}\right)$ were $106.8 \pm 15.1,155.8 \pm 14.6,83.2 \pm 16.0$, and 101.4 $\pm 18.2 \mathrm{mM}^{-1} \mathrm{~s}^{-1}$ for $\mathrm{SPIO} @ \mathrm{SiO}_{2}-\mathrm{NH}_{2}, \mathrm{SPIO} @ \mathrm{SiO}_{2}$, bare SPIO, and SPIO@dextran nanoparticles, respectively.

\section{SPIO nanoparticle uptake evaluated with Prussian blue staining}

The typical Prussian blue staining images of the six different cells internalized with these four SPIO nanoparticles are shown in Figure 3. The visual assessment of each SPIO 


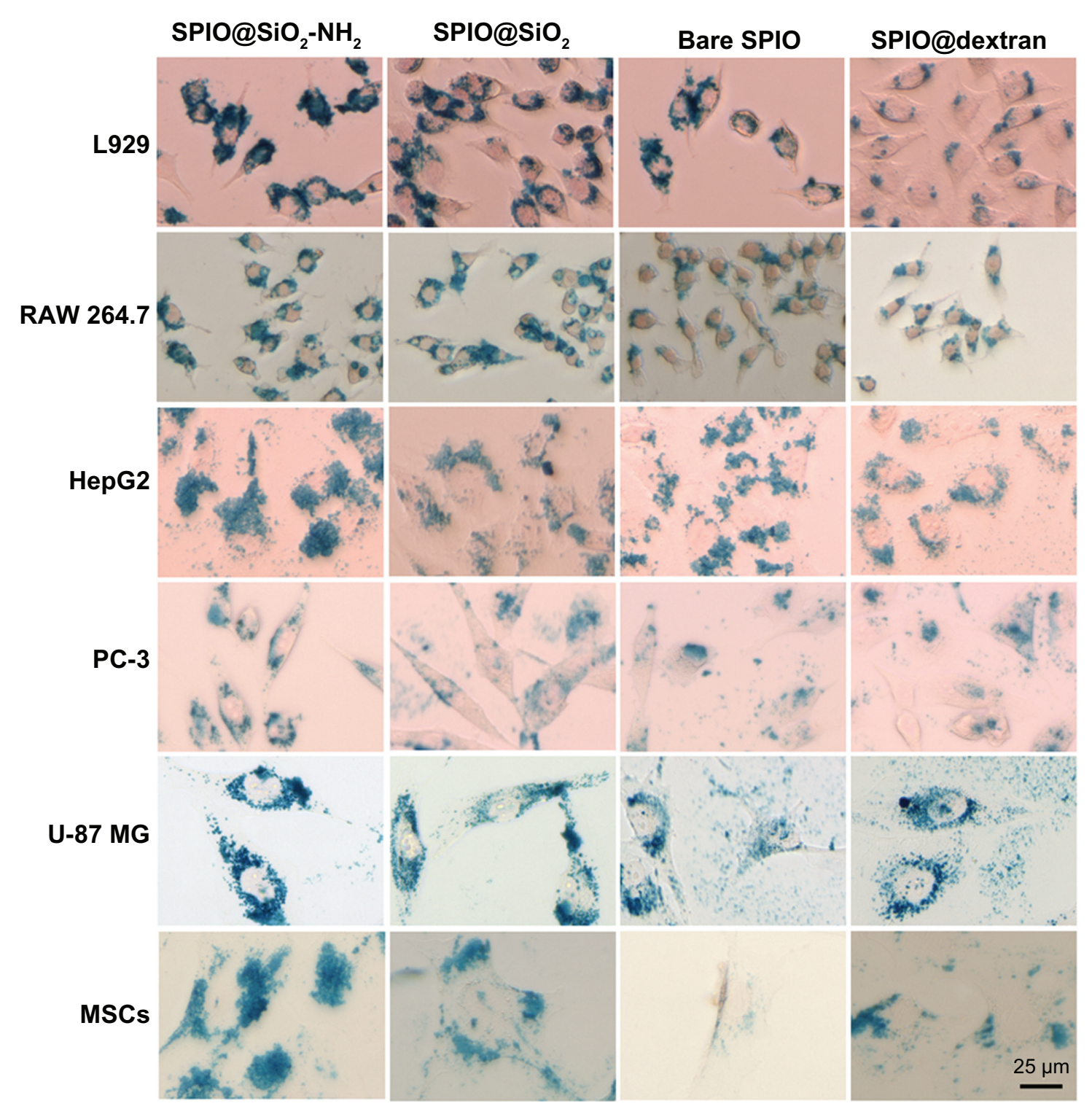

Figure 3 Prussian blue staining of iron in six mammalian cell lines. L929, RAW 264.7, HepG2, PC-3, U-87 MG, and primary cultured mouse mesenchymal stem cells were incubated with SPIO nanoparticles at iron concentration of $4.5 \mu \mathrm{g} / \mathrm{mL}$ for 24 hours.

Notes: The morphology of these cells were not changed, and blue granules were evident at the cytoplasm around the nuclei. Scale bar $=25 \mu \mathrm{m}$.

Abbreviations: SPIO, superparamagnetic iron oxide; SPIO@SiO $-\mathrm{NH}_{2}$, aminosilane-coated SPIO nanoparticles; SPIO@SiO, SiO - -coated SPIO nanoparticles; SPIO@ dextran, dextran-coated SPIO nanoparticles.

nanoparticle for the six cell lines is shown in Table 1 . According to visual assessment (Figure 3 and Table 1), SPIO@ $\mathrm{SiO}_{2}-\mathrm{NH}_{2}$ had a highest cellular uptake efficiency among the four SPIOs. For SPIO@ $\mathrm{SiO}_{2}$, bare SPIO, and SPIO@dextran nanoparticles, there were variations of labeling efficiency among different cell lines, whereas SPIO@SiO $\mathrm{SiO}_{2}$ tended to rank as the second, and SPIO@dextran tended to have lowest labeling efficiency.

\section{Intracellular iron content}

The intracellular iron content for the four types of SPIO nanoparticles in six cell lines is demonstrated in Figure 4.
Comparing the iron uptake of four types of SPIO nanoparticles in the six different cell lines, each cell group treated with $\mathrm{SPIO} @ \mathrm{SiO}_{2}-\mathrm{NH}_{2}$ nanoparticles showed the highest iron content. For SPIO@ $\mathrm{SiO}_{2}$, bare SPIO, and SPIO@dextran nanoparticles, there were variations of labeling efficiency among different cell lines,with SPIO@ $\mathrm{SiO}_{2}$ tending to rank second, and bare SPIO and SPIO@ dextran tending to have lower labeling efficiency. For the same SPIO nanoparticles, the intracellular iron content in different cell lines was variable. For SPIO@ $\mathrm{SiO}_{2}-\mathrm{NH}_{2}$ nanoparticles, the highest accumulation was observed in U-87 MG cells and MSCs. 
Table I Rank order of cellular uptake efficiency of four SPIO nanoparticles by visual assessment

\begin{tabular}{lllll}
\hline Cell line & SPIO@SiO $_{2}-\mathbf{N H}_{2}$ & SPIO@SiO $_{2}$ & Bare SPIO & SPIO@dextran \\
\hline L929 & 1 & $2^{\mathrm{a}}$ & $2^{\mathrm{a}}$ & 3 \\
RAW 264.7 & 1 & 2 & $3^{\mathrm{a}}$ & $3^{\mathrm{a}}$ \\
HepG2 & $\mathrm{2}$ & $3^{\mathrm{a}}$ & 2 & $3^{\mathrm{a}}$ \\
PC-3 & 1 & 2 & $3^{\mathrm{a}}$ & $3^{\mathrm{a}}$ \\
U-87 MG & 1 & 2 & 4 & 3 \\
MSCs & $\mathrm{I}$ & 2 & 4 & 3 \\
\hline
\end{tabular}

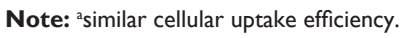

Abbreviations: MSC, mesenchymal stem cell; SPIO, superparamagnetic iron oxide; SPIO@ $\mathrm{SiO}_{2}-\mathrm{NH}_{2}$, aminosilane-coated SPIO nanoparticles; SPIO@SiO , SiO SPIO nanoparticles; SPIO@dextran, dextran-coated SPIO nanoparticles.

A

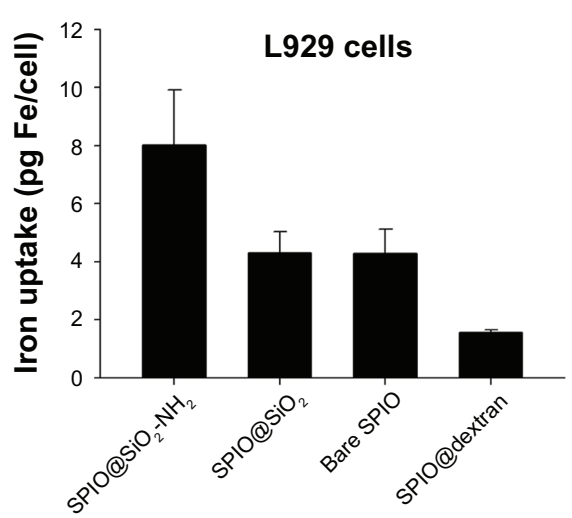

C

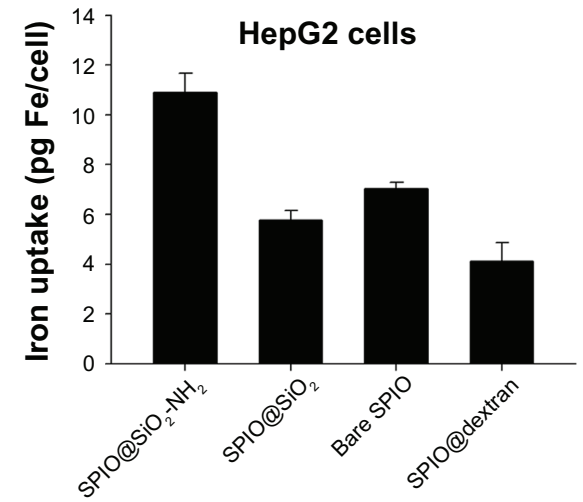

E

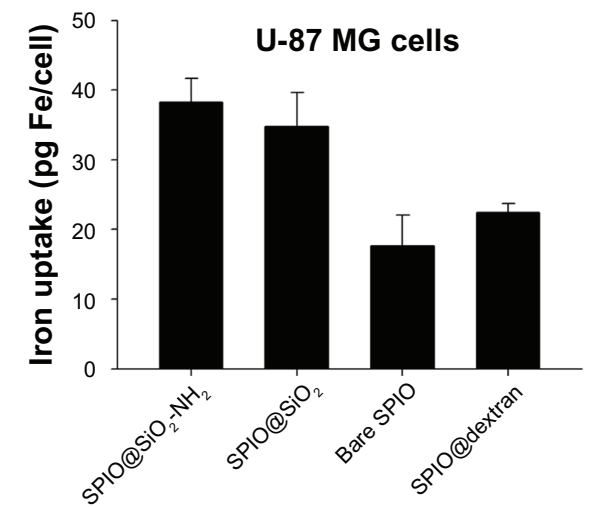

B

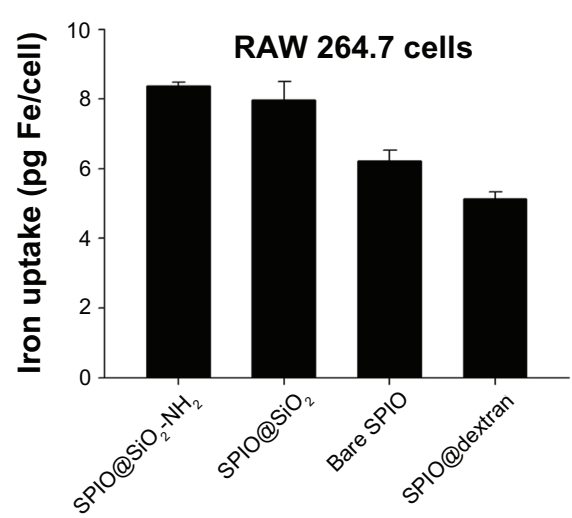

D $\left.\widehat{\overline{\bar{g}}}^{10}\right] \quad$ PC-3 cells

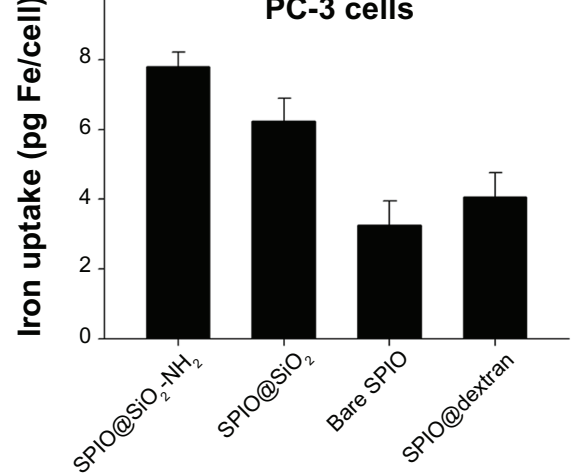

$\mathbf{F}$

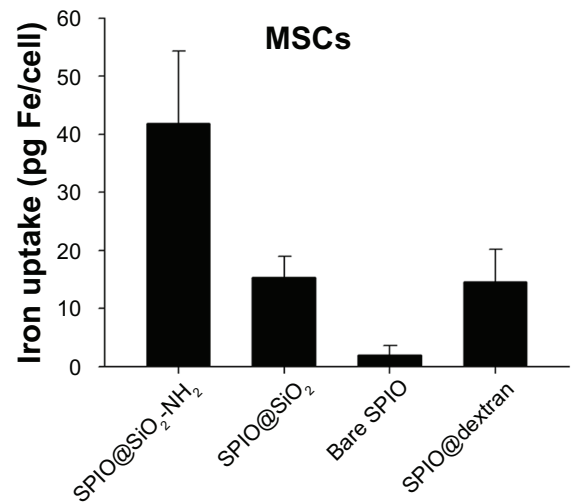

Figure 4 Intracellular iron content study in L929, RAW 264.7, HepG2, PC-3, U-87 MG, and primary cultured mouse MSCs after 24 hours incubation of SPIO nanoparticles with iron concentration at $4.5 \mu \mathrm{g} / \mathrm{mL}$.

Note: Data were expressed as means \pm standard deviations from three experiments.

Abbreviations: MSC, mesenchymal stem cell; SPIO, superparamagnetic iron oxide; $\mathrm{SPIO} @ \mathrm{SiO}_{2}-\mathrm{NH}_{2}$, aminosilane-coated SPIO nanoparticles; $\mathrm{SPIO} @ S i \mathrm{~S}_{2}$, SiO - -coated SPIO nanoparticles; SPIO@dextran, dextran-coated SPIO nanoparticles. 


\section{MRI of MSCs labeled with SPIO nanoparticles}

MRI of MSCs labeled with SPIO nanoparticles is shown in Figure 5. For all four nanoparticles, substantial negative contrast (dark MRI signal) was observed with cell pellets of more than 30,000 cells leading to a "ballooning" effect. For the cell pellets of 10,000 cells, SPIO@ $\mathrm{SiO}_{2}-\mathrm{NH}_{2}$ nanoparticlelabeled cells had stronger MRI signals than that of SPIO@ $\mathrm{SiO}_{2}$ or SPIO@dextran nanoparticles, whereas bare SPIO nanoparticle-labeled cells were not detectable.

\section{Cell viability}

The results of RAW 264.7 cell viability post SPIO incubation is shown in Figure 6. The $\mathrm{SPIO} @ \mathrm{SiO}_{2}-\mathrm{NH}_{2}$, bare $\mathrm{SPIO}$, and SPIO@dextran nanoparticles did not affect the cell viability of RAW 264.7 cells, even at highest iron concentration of $200 \mu \mathrm{g} / \mathrm{mL}$. However, SPIO@SiO nanoparticles negatively affected RAW 264.7 cell viability at iron concentrations from 10 to $200 \mu \mathrm{g} / \mathrm{mL}$ in a dose-dependent manner.

\section{Discussion}

In the present study, monodispersed SPIO nanoparticles coated with aminosilane $\left(\mathrm{SiO}_{2}-\mathrm{NH}_{2}\right), \mathrm{SiO}_{2}$, or dextran, as well as bare SPIO nanoparticles, were synthesized. These four SPIO nanoparticles' cellular uptake efficiencies were evaluated in a number of mammalian cell lines, and their cytotoxicities were assessed with macrophage RAW 264.7 cells. The $T_{2}$ relaxivities $\left(r_{2}\right)$ of these four SPIO nanoparticles are in the range of previously reported SPIO, and compared favorably with known SPIOs of similar sizes. The $r_{2}$ values of VSOP-C184 (diameter 7 nm, Ferropharm, Teltow, Germany), SHU-555C (diameter $21 \mathrm{~nm}$, Schering, Berlin, Germany), and Sinerem (diameter 15-30 nm, Guerbet, France) are $33.4 \mathrm{mM}^{-1} \mathrm{~s}^{-1}$, $38 \mathrm{mM}^{-1} \mathrm{~s}^{-1}$, and $65 \mathrm{mM}^{-1} \mathrm{~s}^{-1}$, respectively. ${ }^{6,7}$ For a passive targeting mechanism such as enhanced permeability and retention effect to work, the size of nanoparticles must be controlled to avoid uptake by the reticuloendothelial system. The nanoparticle size range of 7-15 nm would be suitable from this aspect as well as maintaining sufficient magnetic properties. ${ }^{43}$ SPIO nanoparticles can aggregate under culture medium with high ionic strength. In this study, TEM results indicated that the bare SPIO nanoparticles tended to aggregate in culture medium, while aminosilane or silica coating as well as dextran coating prevented the nanoparticle aggregation.

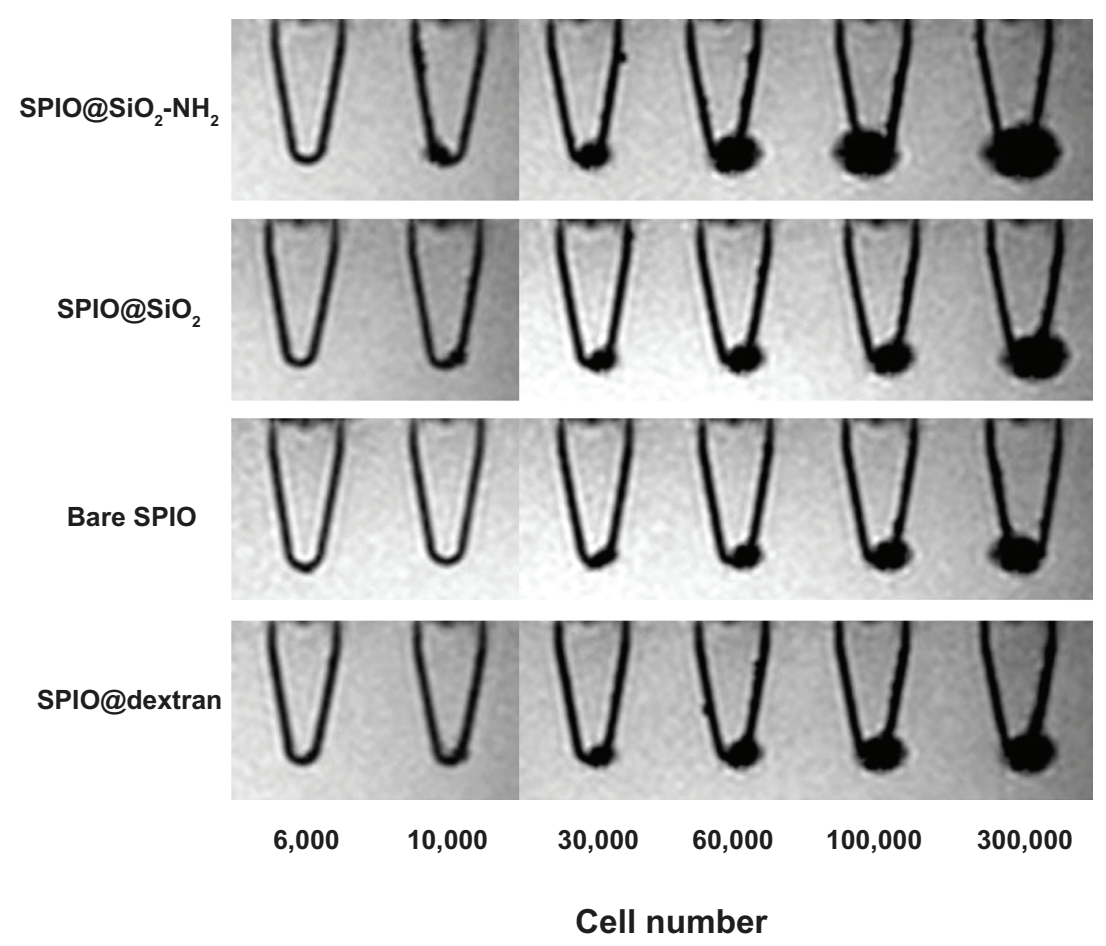

Figure 5 Gradient echo MRI images of mouse mesenchymal stem cell pellets labeled with SPIO nanoparticles (4.5 $\mu \mathrm{g} \mathrm{Fe/mL)} \mathrm{in} \mathrm{Eppendorf} \mathrm{tubes} \mathrm{with} \mathrm{culture} \mathrm{medium.}$

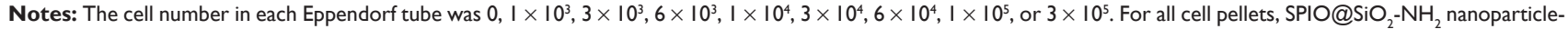
labeled cells had strongest MRI signal void. For the cell pellets of 10,000 cells, bare SPIO nanoparticle-labeled cells were not detectable.

Abbreviations: MRI, magnetic resonance imaging; SPIO, superparamagnetic iron oxide; SPIO@SiO $-\mathrm{NH}_{2}$, aminosilane-coated SPIO nanoparticles; SPIO@SiO , SiO SPIO nanoparticles; SPIO@dextran, dextran-coated SPIO nanoparticles. 


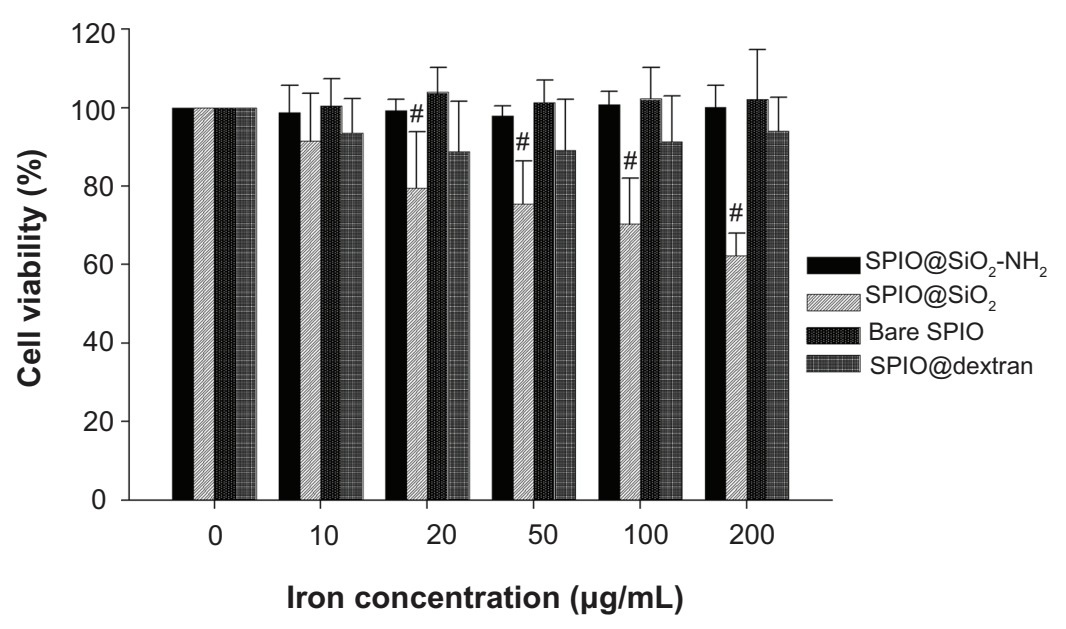

Figure 6 Cell viability of RAW 264.7 cells as determined by MTT assay after incubation with each type of SPIO nanoparticles at different iron concentrations for 24 hours. Notes: Data are expressed as means \pm standard deviations from six experiments; $\# P<0.001$.

Abbreviations: MTT, methylthiazolyldiphenyl-tetrazolium bromide; SPIO, superparamagnetic iron oxide; SPIO@SiO $-\mathrm{NH}_{2}$, aminosilane-coated SPIO nanoparticles; SPIO@ $\mathrm{SiO}_{2}$, $\mathrm{SiO}_{2}$-coated SPIO nanoparticles; SPIO@dextran, dextran-coated SPIO nanoparticles.

Cancerous cell lines MCF-7, MDA-MB-231, HT-29, HepG2, PC-3, and U-87 MG are representative cell lines for studying cancer cell biology. In this study, MSCs were also selected due to the potential application of SPIO nanoparticle labeling for in vivo MRI monitoring. The mouse macrophage cells (RAW 264.7) were selected in this study, as these cells have macrophagic functions, and after in vivo administration of SPIO nanoparticles, these particles may be ultimately cleared from the tissues by the host macrophage. The uptake of SPIO by phagocytic monocytes and macrophages may provide a valuable in vivo tool by which MRI can be used to monitor the involvement of macrophages in inflammatory processes. ${ }^{8,44}{ }^{47}$ As demonstrated in this study, cellular uptake efficiency of SPIO nanoparticles was dependent on the characteristics of cell lines themselves as well as the surface coating of nanoparticles. Among these two factors, the biological nature of cell lines may have the prior importance. MCF-7, MDA-MB-231, and HT-29 cells had poor nanoparticle uptake efficiencies for all four types of SPIO nanoparticles. On the other hand, L929, RAW 264.7, HepG2, PC-3, U-87 MG cells, and mouse bone marrow-derived MSCs displayed substantial nanoparticle cellular uptake capabilities. In the current study, with both Prussian blue staining and intracellular iron content quantification, it was observed that all these six mammalian cell lines showed the highest cellular uptake for $\mathrm{SPIO} @ \mathrm{SiO}_{2}-\mathrm{NH}_{2}$ nanoparticles. Moreover, the intracellular iron content in U-87 MG and mouse MSCs were nearly four times that of any other type of cells. This result may be partly because both U-87 MG and MSCs have bigger cell sizes than the other cell lines (Figures 3 and 4). The authors of this present paper have previously reported that surface amine modification enhances labeling efficiency for rabbit MSCs of SPIO@ $\mathrm{SiO}_{2}-$ $\mathrm{NH}_{2}$ nanoparticles fourfold compared with SPIO@SiO nanoparticles. ${ }^{29}$ That finding was in agreement with the current result of mouse MSCs (Figure 4F). In another study, the high cellular labeling efficiency of SPIO@ $\mathrm{SiO}_{2}-\mathrm{NH}_{2}$ nanoparticles was also seen in human osteosarcoma line U2OS. ${ }^{39}$ The mouse MSC pellets MRI study confirmed the higher uptake with $\mathrm{SPIO} @ \mathrm{SiO}_{2}-\mathrm{NH}_{2}$ nanoparticles can be translated to higher MRI contrast readout (Figure 5).

Surface charge can be important for intracellular delivery of exogenous material. It has been shown that ionic SPIO performed better than nonionic SPIO for cell labeling. ${ }^{48}$ The difference in surface charges between these nanoparticles might provide insights on how the coatings of SPIO affect the cell labeling efficacy. Under $\mathrm{pH}$ value less than 8 , the protonation of amino groups on aminosilane-modified magnetic nanoparticles occur, resulting in surface positive charges ${ }^{49}$ Due to the hydroxyl group present on the surface of SPIO@ $\mathrm{SiO}_{2}$ and bare nanoparticles, these two nanoparticles are negatively charged. ${ }^{21}$ In the present study, the zeta potential measurement illustrated that under $\mathrm{pH}$ 7.4, only $\mathrm{SPIO} @ \mathrm{SiO}_{2}-\mathrm{NH}_{2}$ nanoparticles were positively charged. It is also known that plasma membranes possess large negatively charged domains, which should repel anionic nanoparticles, but cationic surfaces have been shown to facilitate cellular internalization. ${ }^{50}$ This may partially explain why $\mathrm{SPIO} @ \mathrm{SiO}_{2}-$ $\mathrm{NH}_{2}$ nanoparticles have higher cellular labeling efficiency than $\mathrm{SPIO} @ \mathrm{SiO}_{2}$ nanoparticles. The question of whether $\mathrm{SiO}_{2}-\mathrm{NH}_{2}$ coating will enhance nanomaterial's uptake efficiency other than SPIO will be interesting and warrant further study. 
Compared with SPIO@ $\mathrm{SiO}_{2}-\mathrm{NH}_{2}$ or $\mathrm{SPIO} @ \mathrm{SiO}_{2}$ nanoparticles, noncoated and dextran-coated SPIO nanoparticles were found to be less uptaken in all six cell lines. The results showed in DMEM culture medium the colloidal stability of uncoated SPIO nanoparticles is difficult to achieve, which might be one of the reasons for its low cellular uptake efficiency. In agreement with the present results, Kunzmann et al reported that silica-coated SPIO nanoparticles were taken up to a greater extent when compared with dextran-coated particles in primary human macrophages. ${ }^{51}$ The dextran-coated iron oxide nanoparticles do not present sufficient cellular uptake to enable cell tracking, which is probably due to a relatively inefficient fluid-phase endocytosis pathway. ${ }^{52-54}$ During in vitro cellular labeling procedures, some authors use transfection agents to increase the SPIO cell labeling efficiency. ${ }^{55}$ Transfection agents are highly charged macromolecules that have been used to transfect oligonucleotides into cells via electrostatic interaction, which results in endosome formation. By themselves, transfection agents are toxic to cells, and the toxic effect is proportional to the transfection agent concentration. ${ }^{56}$ It is advantageous that a high intracellular labeling efficiency can be achieved with SPIO@ $\mathrm{SiO}_{2}-\mathrm{NH}_{2}$ nanoparticles without the use of any transfection agent.

The results from this study may suggest that cancers with biological features similar to breast cancer MCF-7, MDAMB-231 cells, and colon cancer HT-29 cells may be less amenable to certain types of targeted therapy, while cancers with biological features similar to cancerous cells HepG2, PC-3, and U-87 MG may be more responsive to these types of targeted therapy. This study shows that the U-87 MG glioblastoma cell line had SPIO@ $\mathrm{SiO}_{2}-\mathrm{NH}_{2}$ nanoparticle accumulation four times higher than other cell lines. It is possible that human glioblastoma may be particularly suited for SPIO@ $\mathrm{SiO}_{2}-\mathrm{NH}_{2}$-mediated cellular imaging or targeted therapy.

Surface coating can influence nanoparticle cellular uptake behavior as well as their cytotoxicities. In this study, by way of example, the dependence of cytotoxicity on surface coating of SPIO nanoparticles was investigated by using the mouse macrophage RAW 264.7 cells. The results showed the SPIO@SiO $-\mathrm{NH}_{2}$, bare SPIO, and SPIO@dextran nanoparticles did not affect the cell viability of RAW 264.7 cells, even at an iron concentration of $200 \mu \mathrm{g} / \mathrm{mL}$. However, SPIO@ $\mathrm{SiO}_{2}$ nanoparticles negatively affected RAW 264.7 cell viability at iron concentrations between 10 and $200 \mu \mathrm{g} / \mathrm{mL}$ in a dose-dependent manner. Gozal et al reported that RAW 264.7 cells are sensitive to silica, and exhibited enhanced tumor necrosis factor- $\alpha$ production and nuclear factor- $\mathrm{\kappa B}$ activation, which lead to cell apoptosis. ${ }^{57}$ This result is also consistent with the finding reported by Kunzmann et al that smaller silica-coated SPIO nanoparticles (30 and $50 \mathrm{~nm}$ ) rather than dextran-coated nanoparticles displayed dosedependent cytotoxic effect. ${ }^{51}$ The aminosilane improves the biocompatibility of silica coating which may be partly due to the organic modification of the silica coating and limits the interaction between silica and intracellular organelles.

\section{Conclusion}

This study demonstrated aminosilane-coated SPIO nanoparticles possessed a higher in vitro cell labeling efficiency compared with silica, bare, and dextran-coated SPIO nanoparticles across a number of mammalian cell lines. Aminosilane also improved the biocompatibility of silica coating. Aminosilane-coated SPIO nanoparticles may have promising potential for cellular imaging, drug-targeted delivery, and magnetic separation for blood and serum samples.

\section{Acknowledgments}

This study is partially supported by Hong Kong Innovation Technology Commission (Reference No ITS/066/09).

\section{Disclosure}

The authors report no conflicts of interest in this work.

\section{References}

1. Fernandez-Fernandez A, Manchanda R, McGoron AJ. Theranostic applications of nanomaterials in cancer: drug delivery, image-guided therapy, and multifunctional platforms. Appl Biochem Biotechnol. 2011;165(7-8):1628-1651

2. Meng H, Xue M, Xia T, et al. Use of size and a copolymer design feature to improve the biodistribution and the enhanced permeability and retention effect of doxorubicin-loaded mesoporous silica nanoparticles in a murine xenograft tumor model. ACS Nano. 2011;5(5):4131-4144.

3. Morton JG, Day ES, Halas NJ, West JL. Nanoshells for photothermal cancer therapy. Methods Mol Biol. 2010;624:101-117.

4. Wong HL, Bendayan R, Rauth AM, Xue HY, Babakhanian K, Wu XY. A mechanistic study of enhanced doxorubicin uptake and retention in multidrug resistant breast cancer cells using a polymer-lipid hybrid nanoparticle system. J Pharmacol Exp Ther. 2006;317(3): 1372-1381

5. Garber K. Improved paclitaxel formulation hints at new chemotherapy approach. J Natl Cancer Inst. 2004;96(2):90-91.

6. Wang YX, Hussain SM, Krestin GP. Superparamagnetic iron oxide contrast agents: physicochemical characteristics and applications in MR imaging. Eur Radiol. 2001;11(11):2319-2331.

7. Corot C, Robert P, Idee JM, Port M. Recent advances in iron oxide nanocrystal technology for medical imaging. Adv Drug Deliv Rev. 2006;58(14):1471-1504.

8. Wang YX. Superparamagnetic iron oxide based MRI contrast agents: current status of clinical application. Quant Imaging Med Surg. 2011;1:35-40.

9. Bulte JW, Kraitchman DL. Monitoring cell therapy using iron oxide MR contrast agents. Curr Pharm Biotechnol. 2004;5(6):567-584. 
10. Daldrup-Link HE, Rudelius M, Piontek G, et al. Migration of iron oxide-labeled human hematopoietic progenitor cells in a mouse model: in vivo monitoring with 1.5-T MR imaging equipment. Radiology. 2005;234(1):197-205.

11. Xu H, Aguilar ZP, Yang L, et al. Antibody conjugated magnetic iron oxide nanoparticles for cancer cell separation in fresh whole blood. Biomaterials. 2011;32(36):9758-9765.

12. Moroz P, Jones SK, Gray BN. The effect of tumour size on ferromagnetic embolization hyperthermia in a rabbit liver tumour model. Int $J$ Hyperthermia. 2002;18(2):129-140.

13. Frimpong RA, Hilt JZ. Magnetic nanoparticles in biomedicine: synthesis, functionalization and applications. Nanomedicine (Lond). 2010;5(9):1401-1414.

14. Mahmoudi M, Sant S, Wang B, Laurent S, Sen T. Superparamagnetic iron oxide nanoparticles (SPIONs): development, surface modification and applications in chemotherapy. Adv Drug Deliv Rev. 2011;63(1-2):24-46.

15. McBain SC, Yiu HH, Dobson J. Magnetic nanoparticles for gene and drug delivery. Int J Nanomedicine. 2008;3(2):169-180.

16. Jain TK, Morales MA, Sahoo SK, Leslie-Pelecky DL, Labhasetwar V. Iron oxide nanoparticles for sustained delivery of anticancer agents. Mol Pharm. 2005;2(3):194-205.

17. Lu AH, Salabas EL, Schuth F. Magnetic nanoparticles: synthesis, protection, functionalization, and application. Angew Chem Int Ed Engl. 2007;46(8):1222-1244.

18. Tallury P, Payton K, Santra S. Silica-based multimodal/multifunctional nanoparticles for bioimaging and biosensing applications. Nanomedicine (Lond). 2008;3(4):579-592.

19. Clarke ED, Simmons J, Folz D, editors. Ceramic Transactions. Westerville, OH: American Ceramic Society; 1999:101.

20. Mohanraj VJ, Barnes TJ, Prestidge CA. Silica nanoparticle coated liposomes: a new type of hybrid nanocapsule for proteins. Int J Pharm. 2010;392(1-2):285-293.

21. Zhang C, Wangler B, Morgenstern B, et al. Silica- and alkoxysilanecoated ultrasmall superparamagnetic iron oxide particles: a promising tool to label cells for magnetic resonance imaging. Langmuir. 2007;23(3):1427-1434.

22. Hui C, Shen C, Tian J, et al. Core-shell $\mathrm{Fe}_{3} \mathrm{O}_{4} @ \mathrm{SiO}_{2}$ nanoparticles synthesized with well-dispersed hydrophilic $\mathrm{Fe}_{3} \mathrm{O}_{4}$ seeds. Nanoscale. 2011;3(2):701-705.

23. Kang K, Choi J, Nam JH, et al. Preparation and characterization of chemically functionalized silica-coated magnetic nanoparticles as a DNA separator. J Phys Chem B. 2009;113(2):536-543.

24. LiYS, Church JS, Woodhead AL, Moussa F. Preparation and characterization of silica coated iron oxide magnetic nano-particles. Spectrochim Acta A Mol Biomol Spectrosc. 2010;76(5):484-489.

25. He X, Duan J, Wang K, Tan W, Lin X, He C. A novel fluorescent label based on organic dye-doped silica nanoparticles for HepG liver cancer cell recognition. J Nanosci Nanotechnol. 2004;4(6):585-589.

26. Poovarodom S, Bass JD, Hwang SJ, Katz A. Investigation of the core-shell interface in gold@silica nanoparticles: a silica imprinting approach. Langmuir. 2005;21(26):12348-12356.

27. Zhang F, Sautter K, Larsen AM, et al. Chemical vapor deposition of three aminosilanes on silicon dioxide: surface characterization, stability, effects of silane concentration, and cyanine dye adsorption. Langmuir. 2010;26(18):14648-14654.

28. Sapsford KE, Ligler FS. Real-time analysis of protein adsorption to a variety of thin films. Biosens Bioelectron. 2004;19(9):1045-1055.

29. Wang HH, Wang YX, Leung KC, et al. Durable mesenchymal stem cell labelling by using polyhedral superparamagnetic iron oxide nanoparticles. Chem Eur J. 2009;15(45):12417-12425.

30. Can K, Ozmen M, Ersoz M. Immobilization of albumin on aminosilane modified superparamagnetic magnetite nanoparticles and its characterization. Colloids Surf B Biointerfaces. 2009;71(1):154-159.

31. Ma YJ, Gu HC. Study on the endocytosis and the internalization mechanism of aminosilane-coated Fe3O4 nanoparticles in vitro. J Mater Sci Mater Med. 2007;18(11):2145-2149.
32. Meyre ME, Clerac R, Mornet S, et al. Multilamellar liposomes entrapping aminosilane-modified maghemite nanoparticles: “magnetonions". Phys Chem Chem Phys. 2010;12(39):12794-12801.

33. Massart R. Preparation of aqueous magnetic liquids in alkaline and acidic media. IEEE Trans Magn. 1981;17(2):1247-1248.

34. Kumar S, Wan C, Ramaswamy G, Clemens TL, Ponnazhagan S. Mesenchymal stem cells expressing osteogenic and angiogenic factors synergistically enhance bone formation in a mouse model of segmental bone defect. Mol Ther. 2010;18(5):1026-1034.

35. Reddy AM, Kwak BK, Shim HJ, et al. In vivo tracking of mesenchymal stem cells labeled with a novel chitosan-coated superparamagnetic iron oxide nanoparticles using 3.0T MRI. J Korean Med Sci. 2010;25(2):211-219.

36. Krejci J, Pachernik J, Hampl A, Dvorak P. In vitro labelling of mouse embryonic stem cells with SPIO nanoparticles. Gen Physiol Biophys. 2008;27(3):164-173.

37. Gupta AK, Gupta M. Cytotoxicity suppression and cellular uptake enhancement of surface modified magnetic nanoparticles. Biomaterials. 2005;26(13):1565-1573.

38. Koppolu B, Rahimi M, Nattama S, Wadajkar A, Nguyen KT. Development of multiple-layer polymeric particles for targeted and controlled drug delivery. Nanomedicine. 2010;6(2):355-361.

39. Wang YX, Leung KC, Cheung WH, et al. Low-intensity pulsed ultrasound increases cellular uptake of superparamagnetic iron oxide nanomaterial: results from human osteosarcoma cell line U2OS. J Magn Reson Imaging. 2010;31(6):1508-1513.

40. Denizot F, Lang R. Rapid colorimetric assay for cell growth and survival. Modifications to the tetrazolium dye procedure giving improved sensitivity and reliability. J Immunol Methods. 1986;89(2): 271-277.

41. Du L, Chen J, Qi Y, et al. Preparation and biomedical application of a non-polymer coated superparamagnetic nanoparticle. Int $J$ Nanomedicine. 2007;2(4):805-812.

42. Wang X, Wang P, Dong Z, et al. Highly sensitive fluorescence probe based on functional SBA-15 for selective detection of $\mathrm{Hg}$. Nanoscale Res Lett. 2010;5(9):1468-1473.

43. Berry CC, Curtis ASG. Functionalisation of magnetic nanoparticles for applications in biomedicine. J Phys D Appl Phys. 2003; 36:R198-R206.

44. Saleh A, Schroeter M, Jonkmanns C, Hartung HP, Modder U, Jander S. In vivo MRI of brain inflammation in human ischaemic stroke. Brain. 2004;127(Pt 7):1670-1677.

45. Dousset V, Brochet B, Deloire MS, et al. MR imaging of relapsing multiple sclerosis patients using ultra-small-particle iron oxide and compared with gadolinium. AJNR Am J Neuroradiol. 2006;27(5):1000-1005.

46. Neuwelt EA, Varallyay P, Bago AG, Muldoon LL, Nesbit G, Nixon R. Imaging of iron oxide nanoparticles by MR and light microscopy in patients with malignant brain tumours. Neuropathol Appl Neurobiol. 2004;30(5):456-471.

47. Trivedi RA, U-King-Im JM, Graves MJ, et al. In vivo detection of macrophages in human carotid atheroma: temporal dependence of ultrasmall superparamagnetic particles of iron oxide-enhanced MRI. Stroke. 2004;35(7):1631-1635.

48. Metz S, Bonaterra G, Rudelius M, Settles M, Rummeny EJ, DaldrupLink HE. Capacity of human monocytes to phagocytose approved iron oxide MR contrast agents in vitro. Eur Radiol. 2004;14(10):1851-1858.

49. Tanaka T, Sakai R, Kobayashi R, Hatakeyama K, Matsunaga T. Contributions of phosphate to DNA adsorption/desorption behaviors on aminosilane-modified magnetic nanoparticles. Langmuir. 2009;25(5): 2956-2961.

50. Thorek DL, Tsourkas A. Size, charge and concentration dependent uptake of iron oxide particles by non-phagocytic cells. Biomaterials. 2008;29(26):3583-3590.

51. Kunzmann A, Andersson B, Vogt C, et al. Efficient internalization of silica-coated iron oxide nanoparticles of different sizes by primary human macrophages and dendritic cells. Toxicol Appl Pharmacol. 2011;253(2):81-93. 
52. Wilhelm C, Billotey C, Roger J, Pons JN, Bacri JC, Gazeau F. Intracellular uptake of anionic superparamagnetic nanoparticles as a function of their surface coating. Biomaterials. 2003;24(6):1001-1011.

53. Villanueva A, Canete M, Roca AG, et al. The influence of surface functionalization on the enhanced internalization of magnetic nanoparticles in cancer cells. Nanotechnology. 2009;20(11):115103.

54. Osaka T, Nakanishi T, Shanmugam S, Takahama S, Zhang H. Effect of surface charge of magnetite nanoparticles on their internalization into breast cancer and umbilical vein endothelial cells. Colloids Surf B Biointerfaces. 2009;71(2):325-330.
55. Rogers WJ, Meyer CH, Kramer CM. Technology insight: in vivo cell tracking by use of MRI. Nat Clin Pract Cardiovasc Med. 2006;3(10):554-562.

56. Strand BL, Ryan TL, In't Veld P, et al. Poly-L-Lysine induces fibrosis on alginate microcapsules via the induction of cytokines. Cell Transplant. 2001;10(3):263-275.

57. Gozal E, Ortiz LA, Zou X, Burow ME, Lasky JA, Friedman M. Silica-induced apoptosis in murine macrophage: involvement of tumor necrosis factor-alpha and nuclear factor-kappaB activation. Am J Respir Cell Mol Biol. 2002;27(1):91-98.

\section{Publish your work in this journal}

The International Journal of Nanomedicine is an international, peerreviewed journal focusing on the application of nanotechnology in diagnostics, therapeutics, and drug delivery systems throughout the biomedical field. This journal is indexed on PubMed Central, MedLine, CAS, SciSearch $\AA$, Current Contents ${ }^{\circledR} /$ Clinical Medicine,
Journal Citation Reports/Science Edition, EMBase, Scopus and the Elsevier Bibliographic databases. The manuscript management system is completely online and includes a very quick and fair peer-review system, which is all easy to use. Visit http://www.dovepress.com/ testimonials.php to read real quotes from published authors. 